THE experiments of Heyroth and Loofbourow have established a close correlation between the physiological activity of concentrates of vitamin $\mathrm{B}_{1}$ (after eliminating inactive purines and pyrimidines, which absorb in the same spectral region), and the intensity of the absorption band at $2600 \mathrm{~A}$. 'They have thus provided a welcome confirmation of the proof which we gave in our letter to NATURE of May 14, that vitamin $B_{1}$ is characterised by an absorption covering the mercury line at $2537 \mathrm{~A}$. The detection in their concentrates of inactive substances which absorb light of similar wave-length is of great value as a guide to the conditions undor which the intensity of the band may be used as a measure of the concentration of the vitamin; but the identification of the characteristic band by the method of monochromatic irradiation was independent of the presence or absence of these impurities in the apparently homogoneous crystals which were used in our experiments.

In general, a molecule cannot be destroyed by light which it does not absorb. The only exception to this rule is provided by the phenomenon of photosensitisation. Thus, if light is absorbed by alien molecules of type $\mathrm{A}$, giving riso to chemically active products, such as atoms of chlorine, it may happen that molecules of type B can be destroyed indirectly by the secondary chemical changes which these products are able to effect. This phenomenon, however, depends on a series of contingencies which we regard as unlikely, especially with so stable a vitamin. Moreover, an additional coincidence would be required to account for the parallel effects produced by irradiation and by the action of alkali, as described below.

If this indirect mechanism is excluded, the destruction of physiological activity which resulted from irradiation with tho mercury line $2537 \mathrm{~A}$. proves that light of this wave-length is absorbed selectively by the vitamin and that the absorption band at this wave-length is photochemically active.

The correlation of this band with the biological activity of the vitamin was confirmed by experiments in which both wero destroyed by the action of alkali; but this action is less specific than that of monochromatic light, and was therefore cited only as collateral evidence in support of the more rigid proof which was made possible by the method of monochromatic irradiation.

F. P. BowDen.

Laboratory of Physical Chemistry, C. P. Snow. Cambridge. Oct. 29.

\section{Potency of Vitamin $B_{1}$ Preparations}

RECENTLY (1932), ${ }^{1}$ we have advanced indirect evidence for the belief that crystalline specimens of vitamin $B_{1}$ from baker's yeast, prepared by our methods, were more potent than those of Windaus, Tschescho et al. (1932). ${ }^{2}$ Owing to their courtesy, we have been able to confirm this by direct test. Comparative tests upon pigeons (by curative method) have been made. As birds developed characteristic symptoms, they havo been given alternately by mouth, approximately $14 \gamma(0.014 \mathrm{mgm}$.) of each preparation. (Results by mouth are usually 30 per cent. lower than by injection.) The results were as follows :

$\begin{array}{cccccc}\text { Prep. } & \begin{array}{c}\text { No. } \\ \text { of } \\ \text { birds }\end{array} & \begin{array}{c}\text { Dose } \\ \text { given. }\end{array} & \begin{array}{c}\text { Average } \\ \text { day dose }\end{array} & \begin{array}{c}\text { Standard } \\ \text { error } \\ \text { of mean }\end{array} & \begin{array}{c}\text { Vitamin } B_{1} \\ \text { units/mgm.* }\end{array} \\ \text { G. (Windaus, } & & & & & \\ \text { Tschesche } & 10 & 14 \cdot 2 \gamma & 4 \cdot 31 \gamma & 0 \cdot 63 & 279 \\ \text { et al.) } & 8 & 23-28 \gamma & 4 \cdot 58 \gamma & 0 \cdot 41 & 262 \\ \text { E. (our own) } & 1013 \cdot 8 \gamma & 2 \cdot 56 \gamma & 0 \cdot 35 & 469\end{array}$

The mean difference in potency $G: E$ is $1: 1 \cdot 75$; that is, ours proved to be one and three quarter times as potent. Tested by the usual statistical formula, this difference would occur by chance less than once in fifty trials. It is supported by the tests upon larger doses, and also by reckoning the percentage cures with $14 \gamma$ dose. For $G$ we have $10 / 13$ cured, and for $E 10 / 10$. As we have found it possible to fractionate our crystals still further, we have no hesitation in concluding that more potent vitamin $B_{1}$ can be prepared than preparation $G$, and that this cannot be therefore pure vitamin $B_{1}$.

Henry W. Kinnersley.

J. R. P. O'BRIEN.

Runolph A. Peters.

Department of Biochemistry, Oxford.

* $12 \mathrm{mgm}$. Janson acid clay - 1 pigeon dose.

1 J. Physiol., 76, 1; 1932.

2 Windaus, Tschesche, Ruhkopf, Laquer and Schultz, Z. physiol. Chem., 204, 123; 1932.

\section{A Growth-Stimulating Substance in Fatigued Muscle}

Muscular exercise results in development of the muscles concerned, and it influences other parts of the body. A metabolic product of muscular activity is probably responsible for the muscle hypertrophy, and it is possible that such a hormone may circulate in the blood and stimulate other organs. To our knowledgo the only experimental study of this question is that of Bèlehrádek ${ }^{1}$, who fed tadpoles with artificially fatigued frog muscle. The weight of these tadpoles was increased by 28 per cent compared with controls fed on resting frog muscle, and they metamorphosed earlier than the controls. This has been confirmed by Siebert and Petow. ${ }^{2}$

We have extended this work by feoding blow-fly larvæ with frog muscle fatigued by electrical stimulation through the nerve. In 16 out of 18 experiments the larvæ fed on fatigued muscle grew larger than those fed on resting muscle, the average excess weight being 9 por cent. The larvæ fed on fatigued muscle did not metamorphose earlior than the controls, and their oxygen consumption was unchanged; but the rate of heart beat of the former exceeded that of the latter by 14 per cent.

Work is now being continued on the substances responsible for this growth stimulation and on their mode of action.

Zoological Department,

University of Birmingham. Oct. 27.

1 Arch. Int. Physiol., 22, 376; 1924.

Z. klin. Med., 102, 434; 1925 .

\section{Limiting Mobilities of Some Monovalent Ions and the Dissociation Constant of Acetic Acid at $25^{\circ}$}

VoGEL and Jeffery in a recent letter, ${ }^{1}$ with the same heading as the above, have directed attention to the fact that we omitted, in our recent paper, ${ }^{2}$ to mention that they have published ${ }^{3}$ different figures from ours for the limiting mobilities of ions. Though we should, possibly, have referred to their work in that particular connexion, it was not ignored. The conductance measurements of these authors and the

No. 3290, VoL. 130] 